\title{
NEW PERSPECTIVES ON FAMILY FRIENDLY POLICIES FROM THE STAKEHOLDERS' POINT OF VIEW
}

\author{
Nicoleta Dorina RACOLȚA PAINA, PhD
}

Associate Professor

Faculty of European Studies

Babeș-Bolyai University, Cluj Napoca, România

nicoleta.paina@ubbcluj.ro

Andreea Maria ANDRIEȘ, M.A.

M.A. Graduate

Faculty of European Studies

Babeș-Bolyai University, Cluj Napoca, România andriesandreeamaria@gmail.com

\begin{abstract}
:
Focusing on the importance and the role of family-friendly policies (FFPs), this article argues that a stakeholders' analysis of FFPs enriches the current understanding of this workplace practice. Therefore, what we tried to achieve is a comprehensive stakeholders' review of FFPs, both theoretical and practical, in order to highlight all the standpoints from opposite corners of the power-interests grid. The theoretical part is completed by a practical one, which was conducted in Norway. The collected data (by way of 6 face-toface interviews) was analyzed trough grounded theory and extensive comparison, with the purpose of highlighting the similarities and differences between the answers from each of the FFPs stakeholders. The findings of our field research revealed 4 major themes that represent the summary of the respondents' common opinions related to FFPs: Characteristics (benefits, weaknesses), the Nordic Model of Economy (high female employment rates, equality, strong labor movement), Mentality (good opinion of the society, take it for granted) Involvement of the authorities (trust in the Government, historical changes). The results of the research that led to common main opinions regarding these 4 central themes of FFPs identified among all stakeholders, as well as some differences in the main ideas, represented an unexpected outcome if it were to take into consideration the diversity of needs and characteristics of the different categories of stakeholders involved. These findings bring arguments for the need to reshape the current work-life balance practices for the future, and even consider creating new ones, to benefit a wider and more varied range of actors.
\end{abstract}

Keywords: Family friendly policies, social policies, work-life balance, qualitative research, Norway. 
Issue no. 22/2017

\section{Introduction}

Included in the wide range of work place policies, family-friendly policies (FFPs) are a good way to create value in society, both for the present and most importantly for the future. They are not such an expensive tool that the private and public organizations have at their disposal to use any time for the creation of a healthy and powerful state. These policies are the core element that can ease the balance between work and family life. Why this balance is so important though? The general regard is that you cannot combine them both. You can either have a very successful career or a happy family and this has been the way promoted directly or indirectly by developed countries that wanted people to be focused and work towards the common goal of economic development. However, recently the power has shifted, gender discrepancies in the labor force developments have decreased and a career can easily be combined with family life. The balance between work and personal life has started to grow and FFPs have a great deal of impact and influence since they clearly ease the path towards development.

So far, there is no empiric evidence of the relationship between a balanced life and work efficiency because there has not been yet a comprehensive study that would demonstrate the linkage. However, certain analysis and examples exist in the literature and the results are staggering on the side of a tradeoff between personal life and company loyalty. Organizations that prove to bend the ear to theories that acknowledge the importance of happy employees thrive not only for their own benefit, which is the profit, but they can also flourish in social responsibility.

The current research is meant to shift the discussions related to the issues at hand towards a different approach based on the opinions of all the actors involved. What we suggest is a stakeholders' analysis of FFPs, both theoretical and practical, in order to highlight all the points of view from opposite corners of the power-interests grid. Based on the opportunity of one of the authors, the research behind this article was conducted in Norway, in 2016, first at desk level but continuing with an extensive field research on 
identified relevant stakeholders for family friendly policies.

Among all the countries of The European Economic Community, Norway is on top with one of the most extensive and well established work-life balance systems. In their scenario of a small open economy, with a very high standard of living and with very efficient institutions, the work culture is characterized by efficiency, good business communication, innovation, creativity and empowered employees. This leads to a highly performing economy where the emphasis stays on the human being as worker and citizen. A characteristic of Norwegian professional life is the important work/life balance. There is a general notion that people work to live rather than live to work. Norwegian lifestyle focuses on family values, sports and outdoor life (Nyinorge.no).

The basis is laid by the Norwegian labor system which combines high employment in both men and women, very strong labor legislation, lower and flexible working time, excessive Government spending for the welfare system, cooperation among actors, equality, a high standard of living, substantial benefits and very good arrangements for all the citizens. Trade unions, employer's organizations and public institutions play a key role in the governance of the employment relationship, working conditions and industrial relations structures. They are interlocking parts in a multilevel system of governance (Nergaard, 2014).

In regards to work culture, the Norwegian companies and institutions pay a great deal of attention to tolerance, freedom, personal space, work flexibility, satisfied employees, loyalty, family support, incentives for growing birth rate, equality, father politics, parenthood, (Bjørnholt, 2012), (Peterson, Penner, \& Høgsnes, 2014), (AumayrPintar, et al., 2015), (Adema, Clarke, \& Frey, 2015), (Norwegian Labor and Welfare Administration, 2016), (Skevik Grødem, 2008). The goal is to create a better working life for employees and more benefits and productivity for employers.

Considering the implications in the whole society of any kind of work place policies, we considered that a stakeholders' approach would reveal to what extent are all 
the actors behaving in the same way related to the content, impact, benefits or threats of FFPs. The novelty of this approach is precisely the combination between the implication of all categories of stakeholders relevant to the topic as a component of the desk research, the proposed framework for FFPs - stakeholders' analysis and also the particularities added by Norway, the country where all the interviews were taken, as an integral part of the field research.

In this article we focused on identifying the differences among the answers from the interviewees, this being our major research objective - to clarify if there are new perspectives on FFPs and work life balance from the stakeholders' point of view. Our aim is to see if stakeholders with different powers and interests would be able to influence the current state of FFPs and even impose the creation of new types of work life balance practices in the future.

\section{Perspectives on family friendly policies from the stakeholders' point of} view - literature review

The issue of family friendly policies cannot be discussed separately than the entire development of a company. All the factors involved need to be taken into consideration when assessing the correct situation. This is not just for a narrative purpose but more vigorously for accuracy of the research.

"Family friendly policies" is the expression mostly used in theory. All the literature that deals with this topic puts an emphasis on the word family and mostly it has been regarded as a traditional term (United Nations, 2012). Most benefits that fall under this type of work place policies target families with children and mostly mothers (World Policy Analysis Center from UCLA Fielding School of Public Health, 2014).

However, nowadays only $21 \%$ of families with children at home are traditional families (O'Leary \& Kornbluh, 2009). Families have changes over the past thirty years. Fertility rates have been persistently low in many OECD countries leading to smaller 
families. With marriage rates down and divorce rates up, there are an increasing number of children growing up in sole-parent or reconstituted families. Sole-parent families are of particular concern due to the high incidence of poverty among such households (O.E.C.D., 2011).

Recently, new terms have stated to be used and the most common is "work life balance" that corresponds better with the new developments in regards to families and employees.

The core of organizational culture is based on work place policies, which are essential for a company's long term development and brings to a common denominator the owners, investors, the management team, the employees and other stakeholders by impelling them to work tight together towards the same goals. These policies refer to principles, rules, and guidelines formulated or adopted by an organization to reach its longterm goals. Policies therefore set the limits of what can be done, who should do it and under what circumstances (Katulwa, 2015, pp. 5-6).

Having systematical workplace policies that are well designed, unequivocally implemented and accurately monitored, will create a sustainable organization with powerful and healthy work relations, both hierarchical and functional. Most importantly, by creating policies and procedures that encourage constructive and collaborative behaviors from employees at all levels of the company and inspire a general positive and friendly working environment, the company takes the first steps in preventing unproductive workplace conflicts and providing good customer service (Raines, 2013, p. 131).

FFPs recognize the importance of family in society and they see it as the kernel of human existence both financially and socially. If implemented well and diversified, these policies can be a real gain for everybody involved: the employees, the state, the employer and other stakeholders that might appear. Family friendly workplaces will lead to a more stable community, a healthier society and a more sustainable future. 
The support of families in the workplace developed from the late 19th century, developing mostly maternity leave, health care and social insurance. This was just the beginning and in Europe it went up hill from there to the 1970's when work-family reconciliation policies got their first drive, while in the USA for example, even nowadays this kind of workplace policies do not have the necessary force (Williams, 2010, p. 7).

Several types of FFPs can be implemented at the same time or separately in a company or an organization. They can also take different shapes and be directly aimed at family-work reconciliation or just have an incidental outcome towards this aspect. The size and implementation of these kinds of policies differ also according to the size of the company since it is obvious that a very small new business cannot have the same financial power as a large company or a public institution. Analyzing statistics and reviewing literature in the field, the following FFPs appear to be the most frequent around the globe (World Policy Analysis Center from UCLA Fielding School of Public Health, 2014): flexible hours, paid maternity leave, wage replacement rate of paid leave for mothers, unpaid extra maternity leave provided by companies after the legal paid period but without benefits, paternity leave, work away from the workplace, telecommuting, temporary switch to part time, paid medical leave for children' sickness, paid child education and care, flexible emergency leave, family medical leave, college scholarship or loans awarded to the employees' children, use of the company's facilities for family events, child care facilities at work, the possibility to bring breastfeeding infants at work, elderly care, recommendations for nursery, kindergarten, school, university where it is usually difficult to get a spot, extra health benefits for employees and other members of the family, mentoring and education on family issues, family oriented events organized by the company, internship positions for employees' children, tuition for employees and employees' children's education, family oriented environment, extra leave of absence for parents, providing different miscellaneous gifts for employees and their families, provide the possibility of taking the life partner or children in a business trip on the company's 
Issue no. $22 / 2017$

expenses.

Analyzing all the examples of FFPs found in the specific literature, a clear distinction stands out. FFPs put a big emphasis on the concept of traditional family. Most of these are designed to help the people that have children and go even further to creating incentives for birth rate growth. Historically, as we laid out previously, these work place policies appeared in a time when the traditional family was the basis of society and everybody worked towards preserving that ideal setting. These examples of policies see the family only as 2 parents of opposite sex with one or more children, or contemporary life style has shifted towards other settings.

Another aspect that stands out is the intensive focus that these policies put on maternity, again promoting traditional values, leaving paternity uncovered or even looked upon with dismay.

Work-family policies have been justified and adopted for a diversity of reasons, including the improvement of women's labor force attachment and economic independence, greater gender equality, reductions in family poverty and social inequality, improvements in children's educational outcomes, enhanced work-life balance, increased fertility, improved infant and maternal health, the alleviation of labor shortages, the prevention of under-utilization of women's accumulated human capital, and long term sustainability of social insurance revenues (Hegewisch \& Gornick, 2011).

Being important themes in modern work environment, the issues of work life balance and FFPs have made room into European Union and European Economic Union's discussion topics and furthermore, certain regulation with the aim of improving working conditions.

The EU decision factors agreed that making both work duration and organization more flexible has become a key issue for employers and workers. Employers see working time flexibility as a way of encouraging greater levels of productivity, while employees see it as key to improving work-life balance. Working time flexibility has a key influence on 
Issue no. 22/2017

the labor market participation of men and of women in particular (Aumayr- Pintar, et al., 2015). Related to that, during 2014, several Member States introduced and/or proposed amendments to labor laws that mirror these general trends towards working time flexibility.

Through the Working Time Directive (2003/88/EC) The EU aims to impel Member States to guarantee some basic rights concerning working time for all workers. The legislation dictates that in order to protect workers' health and safety, working hours must meet minimum standards applicable throughout the EU (European Commission).

Currently, The European Commission is reviewing Directive 2003/88/EC through consultation of European workers' and employers' representatives and a detailed impact assessment. One innovative course of action at the EU Parliament that is worth mentioning is the launch of the first European Interest Group on Work-Life Balance on $3^{\text {rd }}$ March 2015. For the first time, the interest group - supported by representatives of politicians, trade unions, business executives, family and sports organizations and representatives of churches and religious communities - discuss how to ensure that EU legislation respects and promotes workers' health and promotes a better balance between family and private life and work. Participants shared the consensus that these objectives do not conflict with the objective of economic competitiveness. On the contrary, competitiveness needs innovation, innovation needs creativity and creativity needs recreation (European Sunday Allience, 2015).

Another key concept that The EU had focused on lately is the flexible organization of the working time. Two main actors lobbied for improving the working conditions:

- Employees on one side argue that employee friendly flexibility improves worklife balance because it makes it easier for workers to manage different life circumstances or job related responsibilities;

- Employers on the other hand argue that working time flexibility allows them to respond to sudden changes in demand, thus maintaining competitiveness. 
Issue no. $22 / 2017$

Working time flexibility is the key to increasing women's labor market participation which is a concern to many Member States (Aumayr- Pintar, et al., 2015). Several countries experienced higher levels of conflict related to work-life balance, thus introduced measured to increase work time flexibility: United Kingdom, Austria, Croatia, Norway all pivoted towards more flexible working hours. On the plus side, working time flexibility gives employers the possibility of greater productivity by adapting working hours to times of higher activities in business, while giving employees the potential to enhance their work-life balance (Aumayr- Pintar, et al., 2015).

Besides work time flexibility, among The EU forums it has highly been discussed the employment conditions, facilities and policies with maternity and paternity leave in particular. Throughout the Member States in 2014-2015, paternal leave was still highly associated with mothers and the maternity leave differed in duration and rate pay from state to state, being clear that there are considerable differences in this regard among The Union. Basically, the issues related to work-life balance are still scarce around The EU's social policies.

Taking into account all the theory aspects, in this paper we have come up with a possible proposal of a different analysis of FFPs that would take into account all the actors involved. Starting from the fact that these kinds of policies touch the entire society with the ripple effects, it is clear that all the stakeholders are extremely important for a more comprehensive understanding of how the FFPs should be drafted. This approach has been analyzed before as a possible starting point but the main stakeholders taken into account were employers and employees (United Nations, 2012), (Tomazevic, Kozjek, \& Stare, 2014) (Barcenas-Frausto, 2009). We consider that there is need to do a deeper stakeholder analysis based on all relevant actors who have both interests and power over the work place policies. 


\section{A possible framework for family friendly policies - stakeholders' analysis}

Overlooking FFPs, it is easily distinguishable the relatively large number of stakeholders that are influenced by family friendly policies and in the same time that have an impact of different intensity on the entire subject. All involved should recognize the interests of each other and try to address them as soon as possible and in a manner that will ensure sustainable relations among actors.

The main reason for choosing the stakeholder approach was that of coverage. Family friendly policies are a subject that brings together under the umbrella all sorts of actors from public to private, from individuals to corporate and also from a national to an international dimension. The stakeholder approach is about groups and individuals who can affect the organization and is about managerial behavior taken in response to those groups and individuals (Freeman, 2010, p. 48).

As a first step in our review we created a S.W.O.T. analysis of family friendly policies from 3 major stakeholders' point of view: the employees, the employer and the authorities.

According to the first S.W.O.T., clearly the employee is the one that has the most benefits from family friendly policies. Also the degree of threats is high enough to make opportunities feebler. Because they are the beneficiaries of these types of policies, the workers have the most to gain. However it is of utmost importance that the incentives are used in a responsible manner and the employees are not tempted to slide into transgression. The misusage of family friendly policies that lead to excesses and abuses are the greatest weaknesses and threats from the part of workers.

Upon the results of the second S.W.O.T. analysis, the employers, company management, the shareholders and the owners are all the key actors of the system that grasps family friendly policies. The threats and weaknesses are high because of the funds spent on corporate policies but the benefits and most importantly the opportunities could heavily thrive. If applied properly and with a sustainable vision, these policies could 
provide strong opportunities for future development. Of course, this entails the absolute need for a visionary management that would create the basis for growth taking into consideration the wellbeing of employees.

On the last SWOT analysis it showed that the authorities are actors that are not involved directly in decision making concerning family friendly policies. However, they can have a great deal of influence over the company's decisions through national policies that can encourage or discourage any type of benefits. From the S.W.O.T. analysis it is easy noticeable that the Government would have sustainable long term benefits from family friendly policies being implemented in both private and public sector. Besides these, adding the very few weaknesses and threats, the authorities should acknowledge the importance of family friendly policies and even more, they should facilitate incentives in order to impel companies to embrace actions towards a better work/personal (family) life balance.

All these being reviewed, we suggested a stakeholder analysis matrix (see Table 1) with the consequent power interest grid (see Figure 1). Why this is relevant consideration is because the matrix brings forward each stakeholder and what is considered of great importance to it. Also, each actor is ranked from low to medium and high based on impact and influence. The impact represents how much interest the stakeholder has in family friendly policies and the influence asserts the power that each stakeholder has over the issue in hand. Thus it is portrayed a canvas that entails all the relevant information for family friendly policies and exhibits its prominence among corporate policies.

Table 1 Stakeholders' analysis matrix

\begin{tabular}{|l|l|l|l|}
\hline $\begin{array}{l}\text { Stakeholder } \\
\text { name }\end{array}$ & $\begin{array}{l}\text { Impact (how } \\
\text { much do the } \\
\text { project impact } \\
\text { them) } \\
\text { INTEREST }\end{array}$ & $\begin{array}{l}\text { Influence (how } \\
\text { much influence } \\
\text { do they have over } \\
\text { the project) } \\
\text { POWER }\end{array}$ & What is important to the stakeholder \\
\hline $\begin{array}{l}\text { Local and national } \\
\text { authorities }\end{array}$ & Medium & Medium & $\begin{array}{l}\text {-a growing economic environment; } \\
\text {-a healthy society; } \\
\text {-profitable companies that pay taxes; }\end{array}$ \\
\hline
\end{tabular}


Issue no. $22 / 2017$

\begin{tabular}{|l|l|l|l|}
\hline & & & $\begin{array}{l}\text {-working employees that pay taxes and } \\
\text { are engaged in market consumption; } \\
\text {-high employment rate; }\end{array}$ \\
\hline $\begin{array}{l}\text { Employees that } \\
\text { have benefited } \\
\text { from family } \\
\text { friendly policies }\end{array}$ & High & Medium & $\begin{array}{l}\text {-his/her own well-being; } \\
\text {-family well-being; } \\
\text {-basic needs fulfillment; } \\
\text {-continuous personal development; }\end{array}$ \\
\hline $\begin{array}{l}\text { Employees that } \\
\text { have not benefited } \\
\text { from family } \\
\text { friendly policies }\end{array}$ & Low & Medium & $\begin{array}{l}\text {-his/her well-being; } \\
\text {-family well-being; } \\
\text {-basic needs fulfillment; } \\
\text { management and } \\
\text { shareholders } \\
\text {-continuous personal development; }\end{array}$ \\
\hline $\begin{array}{l}\text { The } \\
\text { community/the } \\
\text { public (including } \\
\text { the media) }\end{array}$ & High & High & $\begin{array}{l}\text {-productivity; } \\
\text {-profit; } \\
\text {-efficient employees; } \\
\text {-company development; }\end{array}$ \\
\hline $\begin{array}{l}\text { Company } \\
\text { ownership/ CEOs/ } \\
\text { entrepreneurs }\end{array}$ & High & Medium & $\begin{array}{l}\text {-strong families with livable income; } \\
\text {-sustainable companies that can provide } \\
\text { long term steady jobs; } \\
\text {-corporate social responsibility; } \\
\text {-investments; }\end{array}$ \\
\hline $\begin{array}{l}\text { International } \\
\text { Organizations }\end{array}$ & Low & High & $\begin{array}{l}\text {-profit; } \\
\text {-economic growth; } \\
\text {-company development; } \\
\text {-strong and famous brands; } \\
\text {-competitive advantage; }\end{array}$ \\
\hline $\begin{array}{l}\text { The customers } \\
\text {-healthy economic environment; } \\
\text {-high employment rate; } \\
\text {-covering basic needs for human beings; } \\
\text {-happy people; } \\
\text {-profitable companies; }\end{array}$ \\
\hline
\end{tabular}

Source: the authors

After identifying all the actors that might have a say in both drafting as well as implementing family friendly policies, we considered appropriate to create a power-

\footnotetext{
16 The European Union, International Labor Office, United Nations, etc.
} 
interest grid in order to create a map of how the stakeholders need to be taken into account when discussing this topic.

\section{Figure 1 Stakeholders' power interest grid}

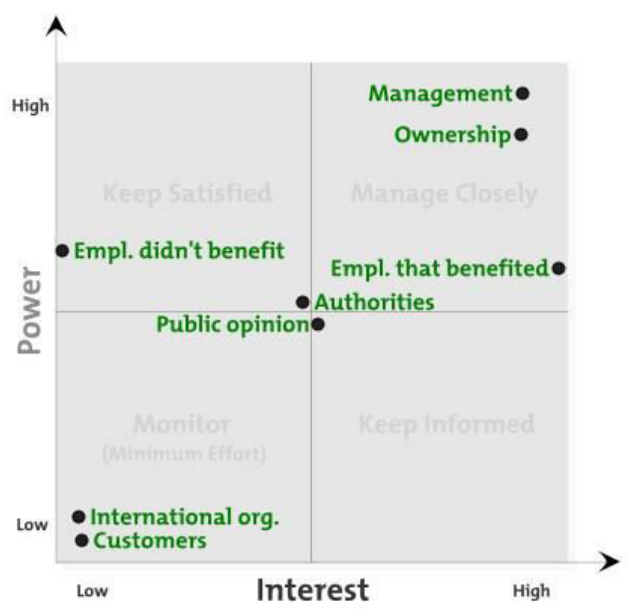

Source: the authors

The power-interest grid (see Figure 1) shows exactly where each category of stakeholders stands based on the previous analysis and it highlights which actors should be kept satisfied, which ones should be managed closely, which ones should be monitored and finally which one should be informed.

The results displayed in these two research tools (see Table 1 and Figure 1) support the previous S.W.O.T. analysis and emphasize the high degree of both interest and power that the management together with the ownership have in dealing with company policies. It is perfectly understandable considering that these two actors have the highest interest in the company's success. Also, they are the decision factors and those who possess the necessary funds, thus the high impact as well. The employees are situated at the opposite side of the interest grid based on the access of the absence of it to family friendly policies, though the power they have over the company is similar considering that employees who 
did not benefit from these policies could act on discontent. The public opinion and the authorities are placed in the middle with medium power and as well medium interest but their effect on family friendly policies should not be attenuated because both impact and influence are for a long run and not just short time benefits.

\section{Methodology for the implementation of the proposed framework}

Considering that the subject of FFPs from the stakeholders' point of view has not been researched extensively and mostly there is not much scientific information in the specific literature, we chose the qualitative research, in order to get a deeper understanding of the theory. Therefore the current research has been conducted on two levels: a qualitative research based on face to face semi structured interviews (all being taken by one of the authors, in Norway, in 2016) and putting the entire data through the sieve of a stakeholders' analysis.

After the identification of all possible stakeholders, we identified at least one respondent for each category but almost all respondents answered from several different capacities. The 6 interviews consisted of approximately 20 questions asked in compliance with the quality and characteristics of the person questioned. The steps for choosing the best respondents consisted of prior research for identifying the proper environment to find the key interest persons to be interviewed both online and offline among academia and professionals in the field, picking the best ones for the purpose of this paper. The age distribution of respondents is between 30 to 50 years old, including all the relevant categories like married, not married, single, with children, without children both men and women. The sample of people interviewed is vast and diversified in order to create a complex picture of family friendly policies and all the actors involved:

- $\quad$ single mother, highly educated, having raised 3 children alone and benefiting from all the family friendly policies that the state had to offer;

- $\quad$ male, single, never married, no children, highly educated, having a stag life; 
- $\quad$ male, married, raised three children, highly educated, benefited from all the family friendly policies that the state had to offer including paternity leave;

- foreigner, coming from a country not so family friendly, highly educated, single, managing position;

- $\quad$ Norwegian, male, not married, one infant newly born outside marriage, high management position;

- female, married, raised 3 children, entrepreneur, former employee, icon in society;

- employees from all the sectors of economy: the public sector, higher education and academia, private sector, entrepreneurs;

In regards to the interviews' interpretation, in order or get the most relevant information we used a content analysis where we examined the interviews to identify the key words, paragraphs and themes, completed with a semi relational analysis where we explored the relationships between the concepts.

Three basic procedures were used: discovering concepts, backing them up with examples and bringing together the commonalities, differences, patterns, structures. Since the interviews were semi structured, the strategy approached was The Grounded Theory (Corbin \& Strauss, 2015), an inductive methodology that systematically generates theory from systematic research. The purpose was to let ideas, concepts and themes emerge from the interviews. The analysis was conducted line by line with open coding, leading to finally grouping up all the similar codes under a certain amount of relevant themes and sub themes that are exhaustive and reflect the purpose of the research.

Given all of the above, we consider the information in this research to be relevant, significant and useful for drawing a conclusion not only because of the quality of the respondents and their diversification but also because in practice, ever since the second interview the basic information started to repeat itself and revealed the most important final deductions. 
One of the difficulties of the paper was gathering the relevant data considering that there have not been robust researches that would link family friendly policies to the performance rate of the company or institution. Mostly, the literature in the field presents examples from different countries around the world, the pros and cons, and sometimes ideas for implementation. From the research of international scholarly data bases there has not been an extensive work with concrete and measurable results on family friendly policies or even on the extent of work/personal life balance over the performance of a company and further more on economy. In order to have tangible results, a project like this would need thick financial analysis before the implementation and considerable data afterwards.

Other problems in assessing the correct data for this research was the lack of information separate than the economic development from discovering oil and the media coverage that makes the issue of family friendly policies more romanced than truthfully assessed.

This paper does not demand to be an expertise for the entire work force in Norway since that kind of undertaking requires a considerably bigger research. Also it is not designed as a comparison to Romania or the European Union, but it takes into consideration a challenge for future works.

Nonetheless, these limitations and difficulties are fully acknowledged and create grounds for a future extended research in the field.

\section{Main findings from the implementation of the proposed framework}

Based in analyzing the interviews trough grounder theory, the approach was comparative. We focused on the opinions of the people interviewed and if there are differences between answers to the same question. This comparative approach allowed us to bring to surface the stakeholders that might have been overlooked and the ones that have been highly praised. 
Basically, the interviews revealed useful ideas and concepts about family friendly policies from historic changes to the influence that it has in society, going through benefits and weaknesses, pros and cons plus personal opinions and points of view.

No visible distinction in opinions could have been identified between the following categories of respondents:

- $\quad$ genders in the case of Norwegian nationals. Both men and women seem to have the same ideas and concepts about family friendly policies. Both genders see benefits and weaknesses the same with absolutely no contradictory arguments like expected;

- married and not married. Norwegian born individuals. No matter if the respondents are married or not, they have the same opinions about family friendly policies with no difference based on gender;

- $\quad$ private business environment or the public sector;

- $\quad$ people with children and people without (Norwegian nationals). Employees with children have benefited of will at some point benefit from a large range of family friendly policies when people with no children will not have the same advantages. But even so, both categories of respondents have the same good opinion about family friendly policies and do not see them as discriminative to childless workers;

- management and the execution part of the business environment among Norwegian nationals. No matter if the respondents are managers, owners, entrepreneurs and they are part of the decision making process or if they are simple workers, professors or other execution positions, they all have the same good thing to say about family friendly policies. The managers are first to notice the challenges related to covering the work positions of employees that benefit from family friendly policies and take time off for their children but still that does not change their good opinion;

- the respondents that were born in Norway and those who have emigrated here. The foreigner that was interviewed has a slightly different opinion considering family friendly policies. He is the only one who mentioned that these policies are discriminative 
to employees without children. Also, he pointed out that in his opinion, Norwegians are not very efficient workers and some of the guilt for this is pinned on family friendly policies that gives employees extended benefits mostly in the leave of absence topic;

All the respondents agreed on several important issues relevant to the topic:

- the Government has done a good job in organizing society in Norway;

- $\quad$ great trust in authorities;

- they all agree and accept the fact that discovering oil was the cause of Norway's wealth. They even go further and place less accountability than expected to them as a performing nation;

- the importance of labor unions in dealing with work force issues like the one currently discussed;

- $\quad$ all the respondents born in Norway and even the one respondent who is a foreigner having lived in the Nordic country for more than five years now are all faithful to the core Norwegian values: equality, freedom, tolerance, respect, solidarity and active participation;

- $\quad$ admit that some employees might take advantage of family friendly policies and abused them for their own and family wellbeing;

- Norway has a very developed system concerning work/life balance and nowadays people take it for granted;

The interviews revealed a few major themes under which all the information positions itself. All these themes and subthemes relate to each other both vertically as well as among them. The concepts do not exist separately and do not create value without the others. It is a combination of factors that have strong and complex connections between them. Without a web like this, the entire system of family friendly policies would have a different face or it would not exist in the way that it does now.

The major themes and subthemes that emerged from the interviews' analysis, which basically show what family friendly policies mean to the subjects interviewed, are: 
Characteristics (benefits, weaknesses), The Nordic Economic Model (high female employment, equality, strong labor movement), Mentality (good opinion of the society, take it for granted) Authorities' involvement (good arrangements in Norway, trust in the Government, historic changes).

All the respondents were able to identify characteristics of family friendly policies both in general and specifically in Norway. Mostly, they talked about how beneficial these policies are for all the actors involved: the employees, the companies, the children, the families and the society in general.

A large amount of respondents (5 out of 6 ) stated that when family friendly policies are implemented, employees are happy and when you have happy employees, not stressed, having a good time when working and also not having to worry about the child's wellbeing, than they are going to do a good job. Besides happy employees, when asked to array benefits, most respondents highlighted several facts and agreed that there are more benefits to family friendly policies than weaknesses.

As a final conclusion about weaknesses, the point made was that it is a double blade sword. If you are too generous with family friendly policies, in the short run it may decrease the productivity of the company. But it might also have positive sides in the sense that people are more satisfied with the job and they are more relaxed if they have more time with the children. So in a way it increases the efficiency for the long run. But it is a double blade sward. It depends on the company. It is very hard to say it in general. But it might be a chance that it decreases the efficiency or the productivity.

An important theme that emerged inductively from the interviews is the fact that family friendly policies have a great deal of influence on The Nordic Economic Model of welfare state, the employment and unemployment rates, inflation, labor movements, wage bargaining system, equality and economic growth. The basic idea is that by having so many people working, with such low unemployment as well, everybody contributes and produces for the society. You get the feeling that you are in it together. Without all the 
people working and on the contrary with people staying at home and not doing anything you do not feel like you are contributing.

Basically the strength of family friendly policies in Norway can be displayed and emerges from a combination between a high percentage of employment, especially among women and a strong labor movement. An interesting point made by the same respondent was emphasizing the importance of strong labor movements and surprisingly, the importance of lobby. It is less likely that the Government give something without somebody asking for it and not only asking, but also lobbying for.

When asked about the society's opinions and the people's mentality on this subject, all the respondents agreed that it is a very positive one. They allege that they have not heard anything negative about family friendly policies and also that most people in Norway are happy, contempt and support the current system set in place. They do not find it discriminative and even more they think that it is fair and that people with children have some privileges.

Even more, some respondents took the conversation towards the threats that the society might face if women do not give birth leading of course to the importance of family friendly policies: if we do not make babies, everything will be lost within one generation. See what happened in Italy or the South of Europe. If you do not have kids or at least two kids, everything will go into recession. So it is very important that women have babies and still work. The fathers should also have a huge portion of the everyday life with the baby and the family. It is not important to make incentives for those who do not have babies. It should be more of an inspiration for those who dare to have babies to continue to do that.

One respondent made an interesting point concerning the mentality of the Norwegian people: there is a common understanding about the fact that both the positions for women and men are equally important. This is the way it is right now and citizens got so used to the very good arrangements that family friendly policies became part of the national culture. 
Concerning the mentality, a point made by three of the respondents of these interviews was that nowadays in Norway they are no longer discussing this subject and Norwegians got so accustomed to having strong family friendly policies that they take it for granted. It is difficult to remember how lucky they are with these very good arrangements. The general feeling is that people pay taxes but they also get so much in return so they work and give their contribution to society. However, some parts of the community are still complaining and they are not as contempt as they should be.

Men and women interviewed all agreed that Norway managed to become an example of good practices in family friendly policies. One reason for fulfillment is the capacity to force men to get involved. Mothers started to work and fathers started to take their place at home. This will let the young fathers to switch with the situation of young mothers end will enable males to be more responsible: In this way you will have new role models among men. They do not have to be unique among ten others that do not stay home with the baby because everybody stays home with the baby. It is the new norm in Norway.

The last recurrent theme recognized throughout all the interviews is the fact that the labor conditions and the social arrangements have changed considerably in Norway in the last thirty years. They have got to this situation during several generations and lately it has changed for the best from only a few days off for young fathers or just a few months off for mothers to the generalized acceptance from nowadays that you should both work and be a parent and the almost forcing of men to take a greater part in raising children and helping with the family life. There is a huge difference in the young men that are becoming fathers - they are spending much more time with the kids from when they are babies up to youngsters. They have relationships with their sons and daughters in a better way than it used to be when I was growing up. So today it is not only the mums who are lucky to live in Norway when it comes to family friendly policies, it is also good for the men becoming young fathers. We consider that the opinion all over, in general, is very positive and today it has become a habit. It is the way it is. We are no longer really discussing it in Norway; it 
Issue no. $22 / 2017$

is just the way it is and the way it should be.

Besides all the ideas expressed so far, there are several other singular concepts that do not fit in the previous categories but are worth mentioning.

When asked to give some examples of family friendly policies from their experience or work place, most respondents talked about maternity and paternity leave as well as flexible working time. These were the most common policies that people from all backgrounds, education level or mentality know the best.

Some respondents mentioned that they know about family friendly policies even from kindergarten. They learn how the society in Norway works since they are very young. The people around them who pass that knowledge are mothers, fathers, neighbors, educators, professors and even others because the society as a whole knows the relevant aspects of this field.

A relevant factor that has been highlighted is the fact that in Norway, authorities are much more attentive and focused towards family friendly policies, working environment, working time, and the freedom of employees. The foreigner respondent even made a comparison to Italy, his home country and concluded that in Norway, the balance between work and family is much better because of the Government who "does enough" in his opinion and the different mentality of the people. It is not the fact that they do not care about their job but much more because the center of life is not the workplace or the job. Even if they have to finish a task, if it is 4 o'clock and they have to go to pick up children from school or kindergarten, they just go. So work is not the most important thing in their lives.

One important aspect that was observed all over the interviews was the answer to the question if family friendly policies and the balance between work and personal life have an influence on the good economic situation of Norway. All the respondents answered that this may be the case but it is important not to forget that the oil is a driving force in the Norwegian economy. The oil money enabled the Government to have funds 
for generous policies. They all agreed that it is not fair to say that it is all about the quality of the Norwegian citizens and authorities; it is basically the overall constant good economic situation of the country.

A contradictory issue noticed among three respondents was the opinion on the absence of new fathers from work. Some opinions in society consider that if the man who usually is the bread winner of the family has to stay away from work with reduced pay that would affect the family's finances and could be a weakness. Some might say that it would interrupt the family's choice, that the family could decide other then what the regulations say and that it is kind of a public interference into private matters. However the majority do not think of this as foible.

Considering the divergent opinions and the practices to be improved, one relevant point of view belongs to the foreigner interviewed. He argues that from his experience he can express the fact that people have the tendency to take advantage if the family friendly policies and his suggestion is to talk about workplace policies in a much broader way: The concept about family should be in a much larger way. Maybe it looks more egoistic but in many cases, people could sometimes benefit from family friendly policies for parents or for other members of the family. It does not matter if it is a parent sick at home or a child, it is the same thing. But for the company this difference matters. It is not like they do not give you time off for taking care of your parents. It is just that the time off for a child is automatic and much easier to get but if it is for other members of the family you would have to apply and it would be more complicated.

\section{Conclusion}

In literature, the FFPs from the stakeholders' perspectives research is not so common, even though this approach is important both from macro to micro levels of the same organization. Even more, it has a ripple effect on society through all the changes that it imposes from the individual to the family itself. 
Issue no. 22/2017

Without doing a sociological analysis, from the current literature it stands out that the traditional version of FFPs is no longer so widely spread. The term "work life balance" better covers the constant changing in the way families behave but actual policies have to emerge from this topic. This trend was also visible in the field research in Norway. Respondents related to new types of family, different in many aspects than the traditional one. Also they reacted to defining the term family and pushed the explanation towards a more loose approach than just 2 married parents of opposite sex with one or more children. In this case, the FFPs need to adapt to new developments.

The added value of this article is given by a stakeholders' analysis of FFPs, both theoretical and practical, in order to highlight all the points of view from opposite corners of the power-interests grid. The desk research focused on the content of FFPs and on all the important stakeholders. The field research that was conducted in Norway because all the respondents permanently live and work there, hence, providing straightforward information right from the source. The collected data (by the way of 6 interviews) was analyzed trough grounded theory and extensive comparison, the purpose being to highlight similarities and difference among answers of FFPs' stakeholders. These interviews were carefully elected to fit in each stakeholder category. Several people responded from different capacities and all of them were important pillars in separate organizations. A substantial result are the 4 major themes that represent the summary of the respondents common opinions related to FFPs: Characteristics (benefits, weaknesses), The Nordic Economic Model (high female employment, equality, strong labor movement), Mentality (good opinion of the society, take it for granted) Authorities' involvement (good arrangements in Norway, trust in the Government, historic changes). Starting from these major themes, the similarities among answers were basically on all levels. Even if this suggests a common understanding in society about this topic, the results of the research are important because it shows that the opinions were similar even from the respondents that were expected to answer differently. For example a single man, not married, without 
children saw the same importance in family friendly policies than a married mother with children.

Respondents that do not have children or are part of a nontraditional family (single with children, with same sex partners, not married, divorces, never had children) brought to light ideas about other types of family friendly policies that would shift the focus from families with children to all the categories of employees. For example they would like the term family to include parents and siblings not only children or spouses. Concerning this aspect, the respondents that are part of a traditional family, do not disagree with the existence of such policies that would benefit all employees and not only those with children but it was not something that they considered on their own.

In conclusion, this research showed that when addressing issues like family friendly policies it is very important and more accurate to discuss it from the stakeholders' point of view. Different stakeholders have totally opposite interests and even more, they have higher or lower power when it comes to influencing the decision making, so having an overview look becomes the true image.

Also, if we take into consideration the stakeholders' perspective, there is an emerging need to change terms and create new policies for the future. The importance of work life balance is constantly growing, so family friendly policies need to keep up with the modern developments and include a wider range of beneficiaries. Also, the revised or completely new policies have to mold on the new forms of families, new liberties and new mentalities that change work place dynamics.

\section{References}

- $\quad$ ADEMA, W., CLARKE, C., \& FREY, V. (2015), "Paid parental leave, Lessons from OECD countries and selected U.S. states." OECD Social, Employment and Migration Working Papers. 
Issue no. 22/2017

- $\quad$ AUMAYR- PINTAR, C., BOEHMER, S., BREMERMANN, M., PARASKEVOPOULOU, A., MCKAY, S., LEWIS, J., et al. (2015), Developments in working life in Europe: EurWORK annual review 2014. Retrieved May 09, 2017, from www.eurofound.europa.eu:

http://www.eurofound.europa.eu/sites/default/files/ef_comparative_analytical_report/field_ef_docu ments/ef1551en.pdf

- $\quad$ BARCENAS-FRAUSTO , J. (2009), "Family-supportive policies: the employer-sponsored child-care approach as an influence of the relationship between work and family outcomes". Academic and Business Reserch Institute.

- $\quad$ BJØRNHOLT, M. (2012), The family in Norwegian society, Norwegian Life and Society. Retrieved May 08, 2017, from University of Oslo: http://www.uio.no/studier/emner/hf/iln/NORINT0500/v07/Family-Norwegian.doc

- $\quad$ CORBIN, J., \& STRAUSS, A. (2015), Basics of Qualitative Reserch, Techniques and Procedures for Developing Grounded Theory, Fourth Edition. Los Angeles: SAGE Publications, Inc.

- $\quad$ EUROPEAN COMMISSION. (n.d.), Employment, Social Affairs and Inclusion - Working Conditions, Working Time Directive. Retrieved May 02, 2017, from ec.europa.eu: http://ec.europa.eu/social/main.jsp?catId=706\&langId=en\&intPageId=205

- $\quad$ EUROPEAN SUNDAY ALLIENCE (2015, December 10), Innovate! Create! The key role of work-life-balance for Europe's sustainable future. Retrieved May 08, 2017, from www.europeansundayalliance.eu:

http://www.europeansundayalliance.eu/site/europeaninterestgroupwork

- FREEMAN, E. (2010), Strategic management, a stakeholder aproach. Cambridge: Cambridge University Press.

- HEGEWISCH, A., \& GORNICK, J. C. (2011), "The impact of work-family policies on women's employment: a review of reserch from OECD countries". Community, Work \& Family, Routledge Taylor and Francis Group, 119-138.

- $\quad$ KATULWA, B. (2015), Leadership \& management made easy, an assessment guide for ILM qualifications. Hamburg: Anchor Academic Publishing. 
- $\quad$ NERGAARD, K. (2014, October 25), Norway: working life, country profile. Retrieved May 09, 2017, from www.eurofund.europa.eu: http://www.eurofound.europa.eu/observatories/eurwork/comparative-information/nationalcontributions/norway/norway-working-life-country-profile

- NORWEGIAN LABOR AND WELFARE ADMINISTRATION (2016), What is NAV? Retrieved May 2017, from https://www.nav.no/en/Home/About+NAV/What+is+NAV

- NYINORGE.NO. (n.d.), New in Norway, practical information from public offices. Retrieved May 05, 2017, from www.nyinorge.no run by The Norwegian Directorate of Integration and Diversity (IMDi): http://www.nyinorge.no/en/Familiegjenforening/New-in-Norway/AboutNorway/History/Values-that-are-part-of-the-Norwegian-mindset-/

- O.E.C.D. (2011), Families are changing. Retrieved May 01, 2017, from oecd.org: https://www.oecd.org/els/soc/47701118.pdf

- $\quad$ O'LEARY, A., \& KORNBLUH, K. (2009, October 09)., Family Friendly for all Families. Retrieved May 01, 2017, from hiverreport.org: http://shriverreport.org/family-friendly-for-allfamilies/

- $\quad$ PETERSON, T., PENNER, A. M., \& HøGSNES, G. (2014), "From Motherhood Penalties to Husband Premia: The New Clhallenge for Gender Equality and Family Policy, Lessons from Norway". American Journal of Sociology, 1434-1472.

- $\quad$ RAINES, S. (2013), Conflict management for managers, resolving workplace, client and policy disputes. Chichester, United Kingdom: Jossey-Bass Business and Management by John Wiley and Sons Ltd.

- $\quad$ SKEVIK GRØDEM, A. (2008), The family in Norwegian society. Retrieved May 5, 2017, from University of Oslo - NOVA, Norwegian Social Reserch: www.uio.no

- $\quad$ TOMAZEVIC, N., KOZJEK, T., \& STARE, J. (2014), “The Consequences of a WorkFamily (Im)balance: From the point of view of Employers and Employees”. International Business Research.

- $\quad$ UNITED NATIONS. (2012), Good Practices in Family Policy Making: Family Policy Development, Monitoring and Implementation: Lessons Learnt. New York: United Nations. 
- WILliAMS, J. C. (2010), Reshaping the work-family debate, why men and class matter. London: Harvard University Press.

- WORLD POLICY ANALYSIS CENTER FROM UCLA FIELDING SCHOOL OF PUBLIC HEALTH. (2014, November 19), A global report card: Are children better off than they were 25 years ago? Retrieved May 09, 2017, from worldpolicycenter.org: http://worldpolicycenter.org/global-agreements/crc-25th-anniversary/crc-at-25-leave-for-infantcare/is-paid-leave-available-for-mothers-of-infants 